\title{
AN EVALUATION OF IMPACT ON QUALITY OF LIFE IN PATIENTS ON ANTIPSYCHOTIC THERAPY AT A TERTIARY CARE CENTRE
}

Hima Bindu Ellabathini ${ }^{1}$, Arun Jyothi Gaddameedi ${ }^{2}$

${ }_{1}^{1}$ Assistant Professor, Department of Pharmacology, Osmania Medical College, Hyderabad, Telangana.

${ }^{2}$ Senior Resident, Department of Pharmacology, Osmania Medical College, Hyderabad, Telangana.

ABSTRACT
BACKGROUND
Antipsychotic drugs utilisation is expanding step by step due to lifestyle changes and increased stress in day-to-day along with
psychiatric disorders. Prevalence of Adverse Drug Reactions (ADRs) with antipsychotic drugs is high, which is influencing the
quality-of-life of patients more than the underlying disease. Hence, this study was taken up to assess Impact on Quality-of-life in
patients using antipsychotics.

\section{MATERIALS AND METHODS}

A prospective observational study was carried out in the Department of Psychiatry at Erragadda Hospital, Hyderabad for 6 months. A total of 189 patients on Antipsychotics were enrolled and Baseline Quality-of-life (WHOQOL-BREF) scale was recorded. On a fixed day in a week they were screened for ADRs, 126 adverse drug reactions (ADRs) occurred. ADRs were monitored using causality assessment scale of Naranjo algorithm. The WHOQOL-BREF scale was used to study the quality-of-life.

\section{RESULTS}

The physical and psychological domain scores of WHO-QOL BREF decrease in patients with ADRs compared to without ADRs. Of the total 189 patients, 126 ADRs occurred. Adverse drug events were mostly with olanzapine (83) followed by risperidone (71) owing to high usage in the government hospital. Majority of the events were classified as probable (34).

\section{CONCLUSION}

The study provides information on the influence of Quality-of-life patients on antipsychotics due to ADRs. Psychiatrists and other health care professionals treating psychiatric patients ought to have information about the possible ADRs and their influence on Quality-of-life following antipsychotic medication and thus should keep an active vigil to prevent, treat and alleviate the adverse health effects due to ADRs.

\section{KEY WORDS}

Antipsychotics, Naranjo Scale, WHO-QOL BREF Score.

HOW TO CITE THIS ARTICLE: Ellabathini HB, Gaddameedi AJ. An evaluation of impact on quality of life in patients on antipsychotic therapy at a tertiary care centre. J. Evolution Med. Dent. Sci. 2018;7(20):2487-2490, DOI: $10.14260 /$ jemds/2018/559

\section{BACKGROUND}

There are many psychiatric disorders like schizophrenia, bipolar disorder, Tourette's syndrome, etc. Along with these, due to lifestyle changes and increased stress in day-to-day life antipsychotic drugs use is increasing. These drugs are capable of causing several adverse drug reactions (ADR).[1] Some of which may be fatal ADRs, which can lead to noncompliance and at times discontinuation of therapy.[2] Monitoring adverse reactions in psychiatry units can play a vital role in early detection of ADRs and alerting physicians to the possibility and circumstances of such events, thereby protecting the user population from avoidable harm and improving quality-of-life. Hence, this study was taken up to assess the impact on Quality-of-life in patients using antipsychotics.

'Financial or Other Competing Interest': None.

Submission 06-04-2018, Peer Review 01-05-2018,

Acceptance 07-05-2018, Published 14-05-2018.

Corresponding Author:

Arun Jyothi Gaddameedi,

Flat No. 102, Ravi Teja Complex,

Gudhi Malkapur Road,

Beside Reliance Fresh,

Mehandipatnam-500028.

E-mail: ajjyothi9@gmail.com

DOI: $10.14260 /$ jemds $/ 2018 / 559$

\section{MATERIALS AND METHODS}

A prospective observational study was carried out in outpatient department of psychiatry at Erragadda Hospital, Hyderabad during January 2013 and June 2013 after Institutional Ethics Committee clearance and informed consent. Psychiatric patients of either gender aged 19 to 65 yrs., irrespective of their psychiatric diagnosis were included in the study. Patients with any acute conditions i.e. organ failure, malignancies, immunosuppressive disorders, substance abuse and any other systemic disorder other than psychiatric disorder were excluded from the study. A total of 189 patients on antipsychotics were enrolled and baseline Quality-of-life (WHOQOL-BREF) scales followed by 1-month scores were recorded. On a fixed day in a week, they were screened for suspected ADRs after initiation of antipsychotic medication. Subjects and their accompanying family members were interviewed and patient's detail history along with current and past treatment was taken. Each participant with ADRs were followed up on regular visits till the ADR resolved.

Causality of event was assessed by Naranjo's criteria. Suspected ADRs with causality less than "possible" will not be considered for further analysis. The Naranjo scale is a questionnaire designed for determining the likelihood of whether an ADR is actually due to the drug rather than the result of other factors. Probability is assigned through a score 
termed definite, probable, possible or doubtful. Score can range from 0 (doubtful ADR) to $\geq 9$ (definite ADR), detailed scoring is described as follows: ${ }^{[3]} \geq 9=$ definite ADR, $5-8=$ probable ADR, $1-4=$ possible ADR and $0=$ doubtful ADR Adverse drug reaction was reported to CDSCO (central drugs standard control organisation) ${ }^{[4]}$ suspected ADR drug reporting form.

All of the participants were given the World Health Organisation Quality-of-life-Brief Form (WHOQOL-BREF) to assess their quality-of-life. The WHO Quality-of-life Assessment (WHOQOL) is a generic quality-of-life instrument that was designed to be applicable to people living under different circumstances, conditions and cultures.[5,6] The WHOQOL is based on a purely subjective evaluation to assess the perceived quality-of-life and in this way differs from many other instruments.[7] WHOQOL also approaches the quality-of-life as a multidimensional concept.[8] From total 189 patients screened baseline physical and psychological domain scores of WHO-QOL BREF was compared with 1month score and was compared with 126 patients with ADRs and 53 without ADRs. If domain scores are scaled in a positive direction (i.e. higher scores denote higher quality-oflife) and vice versa.

\section{Statistics}

Data is represented as mean \pm SD and proportionality and unpaired ' $t$ ' test was used to compare the quality-of-life in patients on antipsychotic drugs. $\mathrm{P}<0.05$ was considered statistically significant. GraphPad prism version 6 is used.

\section{RESULTS}

In our study total of 189 patients on antipsychotics were screened for suspected ADRs, out of which 126 complained with at least one adverse event, thus $66.66 \%$ of our study subjects reported ADRs. Among 126 patients, males represented $42.86 \%(n=54)$ of cases with mean age $41.4 \pm 3.98$ yrs. and BMI of $22.4 \pm 2.7 \mathrm{~kg} / \mathrm{m}^{2}$ and females $57.14 \%(n=72)$ with mean age of $24.4 \pm 2.88 \mathrm{yrs}$. and BMI of $29.4 \pm 2.7 \mathrm{~kg} / \mathrm{m}^{2}$.

Among the psychiatric disorders treated, Schizophrenia $(62 \%)$ was the commonest clinical diagnosis among these cases followed by bipolar affective disorder $27 \%$. A few subjects were taking concomitant medicines for other disorders such as dyspepsia and hypertension. The drug history was taken very carefully in such cases before attributing suspected ADRs to the psychotropic medicines concerned-

\section{Total Number of Patients for each Drug}

Of all the antipsychotic drugs, olanzapine $(n=83)$ followed by risperidone $(n=71)$ were the most common drugs responsible for ADRs, Table I.

\section{Adverse Effect Distribution in Study Population}

Among the ADRs reported, tremors (26.50\%) was the commonest ADR noted followed by weight gain (of $4 \mathrm{~kg}$ or more over the baseline weight- $19.60 \%$ ) and sedation (15.34\%) and constipation (14.49\%) were the most common ADRs in decreasing order of frequency. All ADRs are tabulated in Table II.

Some interesting ADRs were noted during the course of study. One case of Olanzapine induced diabetes mellitus was noted in a 43-year-old schizophrenic patient. She was on
Olanzapine therapy for last 2 years and developed symptoms of polyuria and polydipsia. She had no history of raised blood sugar prior to starting Olanzapine. Her fasting blood glucose level was $237 \mathrm{mg} / \mathrm{dL}$ at the time of study, but returned to normal on substitution of Olanzapine with Risperidone. We also found a rare case of Risperidone induced rabbit syndrome (perioral tremors) in a 34-year-old male Paranoid Schizophrenic patient. One male patient of 42 years developed. Oculogyric crisis immediately within 24 hours after a single dose of parenteral haloperidol.

\section{Causality Assessment using Naranjo's Algorithm Scoring}

Causality assessment revealed that $61.10 \%$ belonged to "Probable" category, whereas $30.16 \%$ were of "Possible" type according to Naranjo's scale- Table III. No ADR encountered turned out to be fatal, life-threatening. Some of the events such as tremor were temporarily disabling, but were managed by the clinicians with corrective medication (such as trihexyphenidyl hydrochloride) or dose modification. Drug induced Parkinsonism was countered with Benztropine tablet. Even drug-holidays were being tried.

\section{Comparison of World Health Organisation Quality-of- life-BREF Scores on Physical, Psychological Domain}

In our study, only physical and psychological domain scores were recorded which are tabulated in Table IV.

Physical Domain Score: It was observed that there was significant improvement in physical domain score taken at 1month post treatment $(14.89 \pm 1.61)$ compared to baseline scores $(14.02 \pm 2.08)$ in patients on antipsychotics $\left({ }^{* * *} \mathrm{p}<0.001\right)$.

It showed that there was a significant decrease in physical domain score taken at 1 -month post treatment $(12.96 \pm 2.11)$ in patients who had ADRs compared to their baseline scores $\left({ }^{* * *} \mathrm{p}<0.001\right)$. Indicating that ADRs in patients is causing great impact on quality-of-life and there was a significant increase in physical domain score taken at 1-month post treatment $(15.26 \pm 2.74)$ in patients without ADRs compared to their baseline scores $\left({ }^{* * *} \mathrm{p}<0.001\right)$. There was a significant difference in physical domain score in patients who had ADRs compared to patients without ADRs.

Psychological Domain Scores: It was observed that there was significant improvement in Psychological domain score taken at 1 -month post treatment $(13.88 \pm 1.71)$ compared to baseline scores $(13.28 \pm 1.64)$ in patients on antipsychotics $\left({ }^{* * *} \mathrm{p}<0.001\right)$.

It showed that there was a significant decrease in Psychological domain score taken at 1-month post treatment $(12.12 \pm 2.13)$ in patients who had ADRs compared to their baseline scores $\left({ }^{* * *} \mathrm{p}<0.001\right)$. Indicating that ADRs in patients is causing great impact on quality-of-life. And there was a significant increase in Psychological domain score taken at 1month post treatment $(14.17 \pm 1.99)$ in patients without ADRs compared to their baseline scores $\left({ }^{* * *} p<0.001\right)$.

Psychological domain scores were significantly affected in patients with ADRs $(12.12 \pm 2.13)$ compared with patients without ADR $(14.17 \pm 1.99)\left({ }^{* * *} \mathrm{p}<0.001\right)$. It was observed that patients with ADRs had significantly lower scores of quality-of-life than patients without ADRs implying that quality-of-life is significantly influenced in patients with ADR compared to patients without ADR. 


\begin{tabular}{|c|c|}
\hline Drug & No. of Patients with ADRs \\
\hline Olanzapine & 83 \\
\hline Risperidone & 71 \\
\hline Haloperidol & 17 \\
\hline Quetiapine & 13 \\
\hline Amisulpride & 7 \\
\hline
\end{tabular}

Table I. Total Number of Patients with ADRs for Each Drug

\begin{tabular}{|c|c|}
\hline Side Effect & No. of Patients- ADRs \\
\hline Tremors & $36(28.7 \%)$ \\
\hline Sedation & $27(21.33 \%)$ \\
\hline Weight gain & $23(18.25 \%)$ \\
\hline Amenorrhoea & $17(13.45 \%)$ \\
\hline Tardive dyskinesia & $13(10.37 \%)$ \\
\hline Constipation, Tachycardia & $\begin{array}{c}8(6.35 \%) \text { cases for each } \\
\text { ADR }\end{array}$ \\
\hline Insomnia & $7(5.53 \%)$ \\
\hline Postural hypotension & $5(3.95 \%)$ \\
\hline Dyspepsia & $4(3.16 \%)$ \\
\hline $\begin{array}{l}\text { Dryness of mouth, Sexual } \\
\text { dysfunction, Parkinsonism }\end{array}$ & $\begin{array}{c}3(2.73 \%) \text { cases for each } \\
\text { ADR }\end{array}$ \\
\hline Anorexia, Hypersalivation & $\begin{array}{c}2(1.58 \%) \text { cases for each } \\
\text { ADR } \\
\end{array}$ \\
\hline $\begin{array}{c}\text { Perioral tremors, Oculogyric } \\
\text { crisis, Impaired glucose } \\
\text { tolerance, Frank diabetes, } \\
\text { Blurring of vision } \\
\end{array}$ & $1(0.79 \%)$ case for each ADR \\
\hline Total & 126 \\
\hline \multicolumn{2}{|c|}{ Table II. Incidence of ADRs in Patients } \\
\hline
\end{tabular}

\begin{tabular}{|c|c|}
\hline $\begin{array}{c}\text { Category Based on } \\
\text { Naranjo's Scale }\end{array}$ & Patients in each Category \\
\hline Highly probable/ definite & $6.35 \%$ \\
\hline Probable & $61.1 \%$ \\
\hline Possible & $30.16 \%$ \\
\hline Doubtful/ unlikely & $6.24 \%$ \\
\hline \multicolumn{2}{|c|}{ Table III. Causality assessment using Naranjo's } \\
Algorithm in Patients
\end{tabular}

\begin{tabular}{|c|c|c|c|c|}
\hline Domains & Baseline & 1-month & With ADRs & $\begin{array}{c}\text { Without } \\
\text { ADRs }\end{array}$ \\
\hline $\begin{array}{c}\text { Physical } \\
\text { domain }\end{array}$ & $14.02 \pm$ & $14.89 \pm$ & $12.96 \pm$ & 15.26 \\
\hline $\begin{array}{c}\text { Psychological } \\
\text { domain }\end{array}$ & 13.28 & $1.61^{* * *}$ & $2.11^{* * *}$ & $\pm 2.74^{* * *}$ \\
\hline Table IV. Comparison of World Health Organisation \\
Quality-of-life-BREF Scores on Physical, Psychological \\
Domain
\end{tabular}

$$
\text { *** } \mathrm{P}<0.001
$$

\section{DISCUSSION}

The present study has reported the impact on quality-of-life due to antipsychotic drugs in psychiatry department in the south Indian context. In our study, we have observed that quality-of-life improved in patients on antipsychotic drugs compared to baseline score without treatment. But patients with ADRs had significantly lower scores of quality-of-life than patients without ADRs implying that quality-of-life is significantly influenced in patients with ADR compared to patients without ADR. Most common drug which caused ADRs was olanzapine. The central nervous system was among the common organ systems affected by adverse drug events. Majority of ADRs (61.10\%) belonged to "Probable" category in Causality assessment. Patients with ADRs had significantly lower scores of quality-of-life than patients without ADRs implying that quality-of-life is significantly influenced in patients with ADR compared to patients without ADR.

In a study by Genevieve $\mathrm{M}$ Hale et al, it was observed that 56 who received antipsychotics 10 suspected ADRs occurred attributed to antipsychotic use. QTc prolongation was the most observed ADR.[9] In our study, 126 suspected ADRs occurred attributed to antipsychotic drug use. Tremors were the most observed ADR. Finding in our study was not in accordance with the study mentioned above.

In Chawla Shalini et al study, total 224 patients enrolled were followed up for a period of 3 months. Of the total 224 patients, 38 adverse drug events occurred. Adverse drug events were mostly with risperidone (10) followed by olanzapine (8) owing to high usage. Majority of the events were classified as probable (34). The occurrence of adverse drug events decreased the scores on physical and psychological domain scores of WHO-QOL BREF at 3 months compared to baseline.[10] In our study from a total of 189 patients screened for ADRs, in 126 patients ADR occurred. Adverse drug events were mostly with olanzapine (83) followed by risperidone (71) owing to its high usage in government hospital where it is available free of cost. Majority of the events were classified as probable (61.1\%). Occurrence of ADRs had significantly lower scores of qualityof-life than patients without ADRs implying that quality-oflife is significantly influenced in patients with ADR compared to patients without ADR. This is in consistent with the available evidence from the existing studies.

A 6-month prospective observation was conducted at an academic psychiatric hospital in New England. This study reported atypical antipsychotic (37\%) to be the most commonly implicated drugs for ADRs. The CNS (66.5\%), cardiovascular and dermatological reactions were among the common organ systems affected by adverse drug events.[11] In our study, the central nervous system was among the common organ systems affected by adverse drug events. The finding in our study is in accordance with the study mentioned above. We could find only one study comparing the association of ADRs with the quality-of-life.[10] But in our study we compared the quality-of-life with ADRs and without ADRs in south Indian context. With this study, we have tried to determine the influence of ADRs on quality-of-life in patients.

\section{CONCLUSION}

The findings from this study confirm that there is an improvement in quality-of-life in psychiatric patients after the treatment is started. But due to high prevalence of ADRs associated with the use of various antipsychotics in our study population, the quality-of-life in psychiatric patients with ADRs significantly decrease compared to patients without ADRs. The presence of an adverse drug reaction compromised the physical and psychological aspect of quality-of-life of patients during the study period. Psychiatrists and other health care professionals treating psychiatric patients ought to have information about the possible ADRs and their seriousness following antipsychotic medication and thus should keep an active vigil to prevent, treat and alleviate the adverse health effects due to ADRs as a result can improve quality-of-life. 


\section{Jemds.com}

\section{ACKNOWLEDGEMENTS}

I thank Dr. Pramod Kumar, Professor and Head and Dr. Hari, postgraduate, Dept. of Psychiatry for their support and timely guidance throughout the study, without which the project would have not been completed. I also want to thank the patients who participated in the study, Erragadda Hospital and Osmania Medical College.

\section{REFERENCES}

[1] Rani FA, Byrne PJ, Murray ML, et al. Paediatric atypical antipsychotic monitoring safety (PAMS) study: pilot study in children and adolescents in secondary - and tertiary-care settings. Drug Saf 2009;32(4):325-33.

[2] Glassman AH, Bigger JT Jr. Antipsychotic drugs, prolonged QTc interval, torsade de pointes and sudden death. Am J Psychiatry 2001;158(11):1774-82.

[3] Naranjo CA, Busto U, Sellers EM, et al. A method for estimating the probability of adverse drug reactions. Clin Pharmacol Ther 1981;30(2):239-45.

[4] Central Drugs Standard Control Organisation form, DGHS:

cdsco.nic.in/Medical_div/General_Formats/Form $\% 20$

44.doc

[5] WHOQOL Group. The World Health Organization Quality-of-life Assessment (WHOQOL): development and general psychometric properties. Soc Sci Med 1998;46(12):1569-85.

\section{Original Research Article}

[6] WHOQOL Group. Development of the World Health Organization WHOQOL-BREF quality-of-life assessment. Psychol Med 1998;28(3):551-8.

[7] Saxena S, Orley J, WHOQOL Group. Quality-of-life assessment: the World Health Organization perspective. Eur Psychiatry 1997;12(Suppl 3):S263S6.

[8] Orley J, Saxena S, Herrman H. Quality-of-life and mental illness. Reflections from the perspective of the WHOQOL. Br J Psychiatry 1998;172(4):291-3.

[9] Hale GM, Kane-Gill SL, Groetzinger L, et al. An evaluation of adverse drug reactions associated with antipsychotic use for the treatment of delirium in the intensive care unit. Journal of Pharmacy Practice 2015: p. 1-6.

[10] Chawla S, Kumar S. Adverse drug reactions and their impact on quality-of-life in patients on antipsychotic therapy at a tertiary care center in Delhi. Indian J Psychol Med 2017;39(3):293-8.

[11] Rothschild JM, Mann K, Keohane CA, et al. Medication safety in a psychiatric hospital. Gen Hosp Psychiatry 2007;29(2):156-62. 